\title{
Environmental Mercury Rising
}

\author{
Carlos Ainza $\cdot$ Jack Trevors $\cdot$ Milton Saier
}

Published online: 12 January 2008

(C) Springer Science + Business Media B.V. 2007

It is popping up in places where it was never expected before, and this heavy metal is having more detrimental effects than ever believed likely. It had been thought that if you avoid certain kinds of fish that are known to have high mercury contamination, you'd be OK. Not so: Surprisingly high levels of mercury have been found in more than 175 species of birds, particularly marine birds. And for the first time, appreciable levels of mercury have been found in wild mammals such as polar bears, bats, mink, otters, panthers and others.

Not surprising is the most common source of the metal. Coal-fired power plants and chemical factories are familiar culprits. Smokestack mercury exists both in particle form, which falls rather quickly to the earth, or in aerosol form that can travel around the globe. Whenever mercuric ions wash into waterways and the oceans, they are taken up by bacteria that partially convert them into more toxic, more volatile methylmercury, a "stickier" form that stays in the

\footnotetext{
C. Ainza $\cdot$ M. Saier $(\bowtie)$

Division of Biological Sciences (0116),

University of California, San Diego,

La Jolla, CA 92093-0116, USA

e-mail: saier@biomail.ucsd.edu

J. Trevors

Department of Environmental Biology,

University of Guelph,

Rm 3220 Bovey Building,

Guelph, Ontario, N1G 2W1, Canada
}

body much longer. However, other sources have been found to be increasingly worrisome. New studies have shown that if hit with increasingly frequent wild fires, drying wetlands are mercury time bombs, releasing centuries worth of the accumulated toxin into the air. While children are most susceptible, mercury poisoning has been shown to affect adults as well, with symptoms including fatigue, vision disturbances, tremors, and permanent brain, kidney and circulatory damage. Biologist David Evers of the BioDiversity Research Institute in Gorham, Maine noted, "It's far more prevalent and at higher levels than considered even a couple of years ago."

At the bottom of the food chain, plankton, shellfish and small baitfish usually have low levels of contamination. Through biomagnification, each time a larger fish eats its prey, the doses of mercury increase so that at the higher end of the food chain, fish like tuna, swordfish and sharks can have thousands of times more mercury than small shellfish and sardines. Humans can avoid eating these contaminated fish, but other animals can't. Thus, rising mercury levels have been found in animals such as bald eagles, loons, mink, otters and alligators. Scientists are not only finding mercury in unexpected places, it seems to be spreading to more and more land animals such as songbirds which feed on contaminated insects. A group studying songbirds in the Northeastern U.S netted over 178 species, and found mercury contamination in many of them. Researchers fear that increasing levels will eventually disrupt the birds' 
reproductive cycles as the metal "creeps up the food chain and continues to biomagnify as it goes."

Wetlands have proven to be a richer source than expected. Marshes in Alaska and Northern Canada are natural sinks for mercury which adheres to damp peat where it readily bioconverts to the methyl form. With increasing drought, due to global warming, increasingly frequent wildfires cause these wetlands to release century's worth of mercury accumulation. As the global mercury levels rise due to such events, more and more species are becoming contaminated.

Cleaning up the mess is the responsibility of the species that caused it. It's our job! The problem starts with coal. Fifty tons of mercury in the U.S., which is about $40 \%$ of the nation's total output, is produced by just over 400 coal-fired power plants. President Clinton attacked this problem with a proposal to require a $90 \%$ cut in power plant mercury by 2008 . President George W. Bush, however, discarded this rule and changed it to a $70 \%$ cut by 2025 . Bush also weakened the Clean Air Act's new-source-review rule, which required power plant owners to install the best available pollution controls when they make major upgrades. However, a Federal court in Washington has pushed back this decision. They strengthened the new-source-review requirements by refusing to sanction a loophole introduced by Bush's pro-corporate Environmental Protection Agency (EPA).

Foreign governments have in general acted more responsibly. Europe, Canada, Japan and even Australia have been reducing their use of mercury over the past 10 years. Once removed from circulation, this harmful metal needn't trouble us again, as long as we remain vigilant. However, it will require international cooperation, and with the U.S. as a major contributor, this seems unlikely until the U.S. federal government changes hands. American voters will need to put the environment as a top priority in future elections. 